\title{
AS PRÁTICAS EDUCATIVAS EM AGROECOLOGIA DO MOVIMENTO DOS TRABALHADORES RURAIS SEM TERRA E OS DESAFIOS FRENTE AS ORDENS IMPOSTAS PELO CAPITALISMO NO CAMPO BRASILEIRO
}

\section{The agroecological educational practices of Landless Rural Workers Movement and the challenges due to the rules imposed by the capitalism in the Brazilian countryside}

\author{
Claudia Maria Bernava Aguillar \\ Doutoranda em Educação na Faculdade de Filosofia e Ciências- UNESP Marília \\ claudiabernava@hotmail.com \\ Maria Alda Barbosa Cabreira \\ Doutoranda em História na Faculdade de Ciências e Letras, UNESP de Assis \\ mabcabreira@yahoo.com.br
}

Artigo recebido em 17/05/2016 e aceito para publicação em 06/10/2016

DOI: $10.12957 /$ tamoios.2016.22841

\begin{abstract}
Resumo
O cenário atual do campo brasileiro faz parte do processo de inserção e intervenção das práticas impostas pelo modo de produção capitalista, capitaneadas pela classe dominante burguesa, que têm como projeto articulador, a implantação e implementação da chamada "revolução verde", a qual revela as políticas ofensivas para dinamizar e aumentar a concentração de riquezas por meio da produção e reprodução do capital, em detrimento da luta dos trabalhadores rurais pelo acesso à terra e o cumprimento de sua função social. Para enfrentar o desafio de minimizar as ofensivas do capital, o Movimento dos Trabalhadores Rurais Sem Terra criou a educação agroecológica, com o objetivo de conceber as manipulações embutidas nas contradições impostas pelo sistema, como a falta de interação das disciplinas e fragmentação do conhecimento em virtude da falta de organicidade dos professores, a dificuldade de apropriação teórica dos alunos, a falta de investimentos para a manutenção das escolas e incentivos à pesquisa em Agroecologia. As práticas educativas em Agroecologia, frente às políticas neoliberais impostas pela classe dominante, se constituem no foco das reflexões iluminadas pela fundamentação teórica e a pesquisa exploratória, as quais contribuem para a análise das questões postas.
\end{abstract}

Palavras Chave: Movimento dos Trabalhadores Rurais Sem Terra; Contradições do Capitalismo no Campo; Práticas Educativas em Agroecologia; Desafios.

\begin{abstract}
The current scenario of the Brazilian countryside is part of the integration process and intervention practices imposed by the capitalist production mode, led by the bourgeois ruling class, which has an articulator project to implement the "green revolution", which reveals the offensive policies to increase the concentration of wealth through the production and reproduction of capital, to the detriment of the rural workers struggle to obtain land and the fulfillment of its social function. In order to meet the challenge of minimizing the offensive of capital, the Landless Rural Workers Movement created the agroecological education, aiming to expose manipulations embedded in the contradictions imposed by the system, such as the lack of subjects interaction and knowledge fragmentation due to few teachers working as team, the difficulty of theoretical appropriation by students, lack of investment for schools maintenance and incentives to research on agroecology. The agroecological educational practices, facing the neoliberal policies imposed by the ruling class, constitute the focus of reflections illuminated by the theoretical foundation and exploratory research, which contribute to the analysis of the posed questions.
\end{abstract}

Key words: Landless Rural Workers Movement; Capitalism Contradictions in the Countryside; Agroecological Educational Practices; Challenges. 


\title{
Introducão
}

As sociedades se organizaram e se desenvolveram junto aos modos de produção criados por elas. No princípio, como estratégia para produzir e atender às necessidades de sobrevivência. Porém, à medida que essas sociedades foram evoluindo, criaram formas de produzir e existir para além das necessidades, constituindo interesses que resultaram em relações de poder.

Um desses modos de produção, intitulado capitalismo, teve seu embrião concebido na Europa a partir do final do século XII, com a crise e desagregação do modo de produção feudal. $\mathrm{O}$ capitalismo se consolidou com a Revolução Industrial realizada primeiramente na Inglaterra, na segunda metade do século XVIII, e depois disseminada para outros países da Europa e também para os Estados Unidos e Japão (século XIX), hoje inserida em todos os continentes.

Para tanto, o desenvolvimento do capitalismo industrial demandou a implantação da concorrência e do progresso técnico, sem os quais se tornaria muito difícil alimentar a produção e o consumo para a obtenção rápida do lucro máximo. A princípio, o espaço apropriado para as relações capitalistas estabelecidas eram as cidades, por conta do comércio, depois o campo para o fornecimento de matérias-primas para alimentar a indústria.

No Brasil, o capitalismo se instala tardiamente, pois numa sociedade escravocrata esse sistema não funcionava, por não haver o trabalho assalariado. Porém, as raízes das desigualdades sócio econômicas ocorrem a partir de sua ocupação pelos europeus, no final do século XV, quando o rei de Portugal, D. Manuel, para desenvolver o mercantilismo, enviou as expedições para ocuparem as terras indígenas e se apropriarem da riqueza existente, o pau-brasil, por meio da exploração do trabalho indígena para cortar e levar a madeira até o litoral, e de lá o transporte para a Europa. A partir do século XVI, é implantada a monocultura para o cultivo da cana de açúcar, nos grandes latifúndios (sesmarias), com a exploração, expropriação e humilhação dos trabalhadores negros importados da África, na condição de escravos.

Para Prado Jr. (2000, p. 117-118):

\begin{abstract}
$\mathrm{Na}$ Agricultura [...], o elemento fundamental será a grande propriedade monocultural trabalhada por escravos. Este tipo de organização agrária, que corresponde à exploração agrícola em larga escala, em oposição à pequena exploração do tipo camponês, não resulta de uma simples escolha, alternativa eleita entre outras que se apresentam à colonização [...]. A grande exploração agrária - o engenho, a fazenda - é consequência natural e necessária de tal conjunto; resulta de todas aquelas circunstancias que ocorreram para a ocupação e aproveitamento deste território que havia de ser o Brasil: o caráter tropical da terra, os objetivos que animam os colonizadores, as condições gerais desta nova ordem econômica do mundo [...].
\end{abstract}

Os fatores, portanto, que vão determinar a estrutura agrária do Brasil são a grande propriedade, a monocultura e o trabalho escravo. Estes fatores, seguindo uma evolução cíclica, se prolongam na formação do Brasil, encontrados, também, no Brasil Império e na agricultura cafeeira do século XIX.

No Brasil República, com exceção do trabalho escravo, a grande propriedade e a monocultura dominam as atividades exportadoras do País, preservando alguns fatores originários do período colonial.

Com a inserção do capitalismo no campo brasileiro, principalmente a partir de meados do século XX, transformaram-se de maneira predatória as relações de produção, gerando desigualdades e negando aos camponeses o direito à terra, à produção e à 
sobrevivência. Percebe-se, portanto, como diz Prado Jr (1981, p. 18), que a questão agrária no Brasil representou e representa um problema social, ou seja, "[...] vêm a ser, em primeiro e principal lugar, a relação de efeito e causa entre a miséria da população rural brasileira e o tipo da estrutura agrária do país, cujo traço essencial consiste na acentuada concentração da propriedade fundiária".

No contexto da inserção do capitalismo no campo brasileiro, encontram-se as práticas capitalistas, entre elas a denominada "revolução verde", nome aparentemente sugestivo, porém um fetiche, pois a continuidade da concentração de terras continua nas mãos de poucos proprietários e das corporações internacionais, sob o domínio do processo de produção explorador e expropriador, dos insumos: sementes, adubos, agrotóxicos, máquinas agrícolas e as técnicas e tecnologias e do trabalho.

Estas práticas têm gerado graves problemas socioambientais, materializados em desempregos, dívidas, doenças, expulsão dos pequenos proprietários, poluição e todo tipo de infâmia sobre aqueles que estão à margem do desenvolvimento (in)sustentável, o qual permeia o campo e atinge os trabalhadores, nas diferentes regiões do Brasil.

Gonçalves (2008, p. 20) define a revolução verde como:

[...] um pacote tecnológico que resultou na industrialização da agricultura brasileira e, consequentemente, no aumento da produção agropecuária, no aumento da exploração da mais-valia social e concentração do capital em suas várias frações, sobretudo a comercial, a agroindustrial, a industrial, a financeira e o fundiário. A organização e a difusão, da 'Revolução Verde' foi amplamente 'regada' por significativas somas de recursos provenientes de fundos públicos, privados e de agências multilaterais de desenvolvimento, cuja implementação 'arrebentou' e continua a 'arrebentar' com as lógicas econômicas e organizativas ditas 'tradicionais', entre as quais as comunidades camponesas, indígenas, quilombolas, faxinalenses, etc.

Para Novaes (2012), este fenômeno é denominado de economia política do golpe verde, pelo novo ciclo de acumulação primitiva, como roubo e grilagem de terras, assassinato de lideranças, roubo do conhecimento indígena; pela concentração ou domínio da terra por corporações internacionais; pelas fusões e aquisições no ramo das sementes e agrotóxicos por algumas grandes corporações dos países nórdicos, por uma "revolução" biotecnológica (novos agrotóxicos e sementes transgênicas) e na ausência de autonomia dos pequenos produtores, cada vez mais trabalhando para bancos e atrelados a corporações agroindustriais.

Como consequências da economia política do golpe verde, ressalta-se:

[...] a concentração da terra, aumento do desemprego no campo; degradação dos solos; comprometimento da qualidade e quantidade dos recursos híbridos; devastação de florestas e campos nativos; empobrecimento da diversidade genética dos cultivares, plantas e animais; contaminação da água e dos alimentos consumidos pela população; aumento das alergias, mortes ou invalidez; aumento da mercantilização e proletarização do campo, além do endividamento dos pequenos produtores e fechamento de escolas do campo, dentre outras (NOVAES et al., 2015, p. 125).

Do ponto de vista da mecanização, o Brasil tem hoje uma agricultura comercial desenvolvida, com investimentos em tecnologias, controlada pelas grandes corporações, como a Monsanto, a Basf, Bayer, Syngenta e outras, que fornecem e controlam a comercialização de sementes transgênicas e de agrotóxicos, colocando o País como maior consumidor desses produtos, com o intuito de produzir cada vez mais para atender ao mercado externo em forma de comodites. 
O cenário atual reflete o controle excessivo dessas corporações sobre o campo, os trabalhadores rurais e suas lutas, com a investida do capital e a ideologia neoliberal. Neste cenário, destaca-se o Movimento dos Trabalhadores Rurais Sem Terra, que luta contra a exclusão e pelo que deveria ser de direito, a terra, via reforma agrária, com a implantação de políticas públicas destinadas ao desenvolvimento socioeconômico dos assentamentos rurais.

Como ação contra-hegemônica ao agronegócio, ou seja, contra a hegemonia do capitalismo no campo, o Movimento dos Trabalhadores Rurais Sem Terra teoriza e coloca em prática, por meio de seus princípios pedagógicos, a Agroecologia, que para o movimento,

[...] faz uma ponte entre o conhecimento tradicional e a ciência integradora de várias áreas, valorizando tanto as inovações tecnológicas que ajudam a enfrentar os problemas vinculados à produtividade da plantação, quanto o camponês como sujeito fundamental para o trabalho no campo, reestruturando socialmente a comunidade agrícola e a agricultura familiar, de onde advém $70 \%$ dos alimentos para consumo no mundo, de acordo com dados do grupo etc. (MST, 2015).

Levando em consideração as dificuldades do enfrentamento dos movimentos sociais às ofensivas do capital, procura-se, por meio deste trabalho, compreender quais são os desafios da educação agroecológica do movimento social em questão frente às práticas capitalistas impostas ao Brasil.

Problematizar sobre as políticas ditadas pelo capitalismo para o campo brasileiro, requer mergulhar nas contribuições do método materialista histórico e dialético, os quais objetiva a constante busca de relações, particularidades e detalhes, como possibilidade de captar o movimento dessas políticas e entendê-las em sua totalidade.

Desta forma, utiliza-se como metodologia neste trabalho, a pesquisa exploratória através da fundamentação teórica e exemplos que estimulem a compreensão (GIL, 2002). Como diz Burawoy (2014, p. 32-33), deve-se sempre partir da teoria: "Sem a teoria, somos cegos: nós não podemos enxergar o mundo". Assim, a pesquisa teórica se faz importante ao fornecer subsídios para a compreensão da realidade, ao proporcionar o ponto de partida para o estudo de transição do modelo do agronegócio ao agroecológico, ou seja, as práticas contra-hegemônica do Movimento dos Trabalhadores Rurais Sem Terra no campo brasileiro por meio da educação escolar das crianças e jovens acampados e assentados, que venha provocar mudanças para a formação de um senso crítico capaz de transformação social, política, cultural e humana.

\section{Movimento dos trabalhadores rurais sem terra e a agroecologia}

O Movimento dos Trabalhadores Rurais Sem Terra nasceu formalmente em janeiro de 1984, após várias ocupações e manifestações dos trabalhadores rurais pela democracia da terra e da sociedade, que vinham ocorrendo no Brasil desde o final da década de 1970. Oficializou-se no $1^{\circ}$ Encontro Nacional, em Cascavel, no Paraná, com o objetivo de lutar pela terra, pela reforma agrária e por mudanças sociais. Como diz Caldart (2001, p. 207),

O movimento dos Trabalhadores Rurais Sem Terra, também conhecido como Movimento dos Sem Terra ou MST, é fruto de uma questão agrária que é estrutural e histórica no Brasil. Nasceu da articulação das lutas pela terra, que foram retomadas a partir do final da década de 70, especialmente na região Centro-Sul do país e, aos poucos, expandiu-se pelo Brasil inteiro. O MST teve sua gestação no período de 1979 a 1984, e foi criado formalmente no Primeiro 
Encontro Nacional de Trabalhadores Sem Terra, que se realizou de 21 a 24 de janeiro de 1984, em Cascavel, no estado do Paraná.

Este movimento social pela construção de uma "sociedade mais justa, sem explorados nem exploradores" no Brasil (MST, 2016), se valeu do setor de educação com $\mathrm{o}$ intuito de garantir às crianças dos acampamentos e assentamentos o direito à escola.

\begin{abstract}
Durante os primeiros anos de luta, os Sem Terra reunidos sob a bandeira do MST tinham como prioridade a conquista da terra. Mas eles logo compreenderam que isso não era o bastante. Se a terra representava a possibilidade de trabalhar, produzir e viver dignamente, faltava-lhes um instrumento fundamental para a comunidade de luta.

A continuidade a luta exigia conhecimentos tanto para lidar com assuntos práticos, como para entender a conjuntura política econômica e social. Arma de duplo alcance para os Sem Terra, a educação tornou-se prioridade do Movimento (MST, 2016)
\end{abstract}

Desta forma, ao longo da história deste movimento social, foram construídas mais de 2 mil escolas públicas em acampamentos e assentamentos por todo País, garantindo educação escolar à 200 mil crianças, adolescentes, jovens e adultos, onde 50 mil adultos foram alfabetizados e 2 mil estudantes efetuaram matrículas em cursos técnicos e superiores (MST, 2016).

As escolas do Movimento dos Trabalhadores Rurais Sem Terra têm como princípio pedagógico a aprendizagem e o ensino a partir da realidade dos acampados ou assentados, isto é, daqueles que vivenciam uma realidade de luta pela terra. "Realidade é o meio em que vivemos. É tudo aquilo que fazemos, pensamos, dizemos e sentimos na nossa vida prática. É o nosso trabalho. É a nossa organização [...]” (MST, 1992, p. 03).

O planejamento das atividades escolares leva em conta a realidade: "Planejar é refletir antes de agir. [...] quando a gente não planeja, por mais que queira fazer um ensino diferente, na prática, acaba repetindo o velho, o tradicional. Foi assim que nos educaram. Foi assim que trabalhávamos até agora [...]" (MST, 1992, p. 07). Este princípio norteia o Ensino Fundamental, o Ensino Médio e a Educação Profissional presentes nos acampamentos e assentamentos de trabalhadores rurais.

As práticas educativas em Agroecologia deste movimento social é um exemplo de Educação Profissional a partir da realidade, por meio de uma gestão democrática e de formação humana. Nestes cursos percebe-se a articulação da ação política na luta por Reforma Agrária com a educação escolar, numa tentativa de transformação humana e social.

Lima (2011, p. 77) pontua que:

[...] a Reforma Agrária defendida pelo MST aponta a Agroecologia como alternativa econômica e ambiental. As práticas educativas em Agroecologia têm como intencionalidade política e pedagógica um projeto educativo emancipatório que, para a realidade do campo, está associado ao direito à educação escolar e técnica. O entendimento é que, nos assentamentos conquistados pelas famílias Sem Terra, podem se construir alternativas coletivas no interior da práxis política organizativa do MST que inibam a reprodução das relações sociais capitalistas [...].

Percebe-se que para este movimento social, as práticas educativas em agroecologia são, além de soluções para os problemas ambientais, alternativas socioeconômicas e culturais, um projeto político pedagógico para a emancipação humana.

Gonçalves (2008, p. 199) diz que se os objetivos do Movimento dos Trabalhadores Rurais Sem Terra são a Reforma Agrária, a soberania alimentar e a luta contra o 
agronegócio, a agroecologia entra em cena como referência de agricultura para a autonomia camponesa e superação do capital. Desta forma, centros e escolas de formação, de capacitação técnica em agroecologias foram criados, a partir "[...] do início dos anos 2000, quando o MST passou a se preocupar tanto em se qualificar para atender às demandas de assistência técnica aos assentados, quanto processar a mudança da matriz produtiva" (GONÇALVES, 2008, p. 239).

Assim, as práticas educativas em agroecologia entram, de maneira significativa, na agenda do movimento a partir dos anos 2000.

Desde 2002, o Movimento tem desencadeado ações para consolidar práticas educativas em Agroecologia visando à formação política e técnica dos sujeitos Sem Terra. Esta proposta levou ao surgimento de mais ou menos 26 escolas de Agroecologia do Movimento em todo o Brasil, com a intenção de formar técnicos voltados para a criação das condições gerais de produção e reprodução da Agroecologia (SANTOS, 2014, p. 61).

Como verifica Santos (2014), a Agroecologia é entendida pelo Movimento dos Trabalhadores Rurais Sem Terra como um campo de conhecimento de caráter multidisciplinar na formação de trabalhadores rurais por meio de princípios e conceitos ecológicos para o manejo sustentável, levando em consideração a preocupação com o esgotamento do solo, a degradação dos recursos naturais e a produção sem a exploração da mão de obra.

Desta forma, Guhur e Toná (2012, p.66), citando a Via Campesina e o Movimento dos Trabalhadores Rurais Sem Terra, ressaltam que a Agroecologia inclui:

[...] o cuidado e defesa da vida, produção de alimentos, consciência política e organizacional [...]. Compreende-se que ela seja inseparável da luta pela soberania alimentar e energética, pela defesa e recuperação de territórios, pelas reformas agrária e urbana, e pela cooperação e aliança entre os povos do campo e da cidade.

A agroecologia se insere, dessa maneira, na busca por construir uma sociedade de produtores livremente associados para a sustentação de toda a vida [...], sociedade na qual o objetivo final deixa de ser o lucro, passando a ser a emancipação humana.

Conforme Santos (2014, p. 60), as práticas pedagógicas na educação profissional em Agroecologia do Movimento dos Trabalhadores Rurais Sem Terra são orientadas pelos princípios educacionais deste movimento social, tais como: a autogestão, a participação efetiva, os tempos educativos, o trabalho, a pesquisa, auto-organização dos alunos e a gestão democrática.

A gestão democrática e a auto-organização dos alunos fazem parte dos Projetos Políticos Pedagógicos destas escolas. Dal Ri e Vieitez (2008, p. 224) destacam que a gestão democrática "[...] compreende dois pontos fundamentais: a direção coletiva dos processos pedagógicos e; a participação de todos os envolvidos no processo de gestão da escola”. Já auto-organização dos estudantes, expressão tomada de Pistrak (educador soviético) pelo Movimento dos Trabalhadores Rurais Sem Terra, diz respeito ao coletivismo:

De acordo com Pistrak, a aptidão para o trabalho coletivo é adquirida no trabalho coletivo, e esse é um problema que a escola precisa enfrentar. Mas a aptidão para trabalhar coletivamente significa, também, aprender tanto a dirigir quanto a obedecer dependendo da necessidade. Para atingir esse objetivo, na auto-organização das crianças faz-se necessário que todas, na medida do 
possível, ocupem sucessivamente tanto a função de dirigentes como as funções subordinadas (DAL RI; VIEITEZ, 2008, p. 225).

O trabalho coletivo e o autogoverno democrático fazem parte das ações educativas do Movimento dos Trabalhadores Rurais Sem Terra, que se movem dentro de um sistema capitalista, lidando constantemente com categorias liberais hegemônicas. Para Dal Ri e Vieitez (2004, p. 55), as categorias principais da educação do movimento em questão "[...] são o enfoque de classe, a autogestão, a conjugação do ensino com o trabalho produtivo e o estudante trabalhador". Entretanto, "[...] esses princípios são válidos quando se pensa numa ação contra-hegemônica [...]?".

Deve-se, portanto, destacar os desafios educacionais no enfrentamento às ofensivas do capital, da educação agroecológica do Movimento dos Trabalhadores Rurais Sem Terra frente às práticas capitalistas impostas ao Brasil.

\title{
Desafios da educação agroecológica frente as práticas capitalistas no campo $\underline{\text { brasileiro }}$
}

A pedagogia e as práticas educativas em Agroecologia do Movimento dos Trabalhadores Rurais Sem Terra estão sendo elaboradas e desenvolvidas dentro da realidade social capitalista, ou seja, se movem dentro de um Estado capitalista que "não passa de um comitê para administrar os negócios comuns da classe burguesa como um todo" (MARX; ENGELS, 2008, p. 12).

O Estado é expressão da classe dominante, um aparelho repressivo e hegemônico da burguesia, formado pela sociedade política e pela sociedade civil representada por organizações responsáveis pela elaboração e difusão da ideologia burguesa, transmitindo valores, normas, visão de mundo, ideias, crenças, comportamento etc., isto é, uma ideologia. $\mathrm{Na}$ sociedade capitalista, as organizações da sociedade civil (organização religiosa, organização política partidária, organização sindical, organização profissional, organização midiática e organização educacional) atuam como instrumento de reprodução e inculcação da ideologia dominante (COUTINHO, 1989).

O Movimento dos Trabalhadores Rurais Sem Terra, dentro deste contexto, acirra seu enfrentamento ao capitalismo e sua ideologia. Como diz Guhur (2010), no início do século XXI, este movimento social ampliou ainda mais suas lutas e sua concepção de Reforma Agrária, numa oposição ao capitalismo internacionalizado, ao agronegócio, ou seja, as políticas neoliberais praticadas no Brasil durante o final do século XX e início do século XXI. Para o setor de educação, este período se caracteriza pelo lema "Todas e todos Sem Terra estudando! ”. O estudo é compreendido “[...] em sentido amplo, que está para além da escolarização, mas se liga a ela na busca do estudo sistemático, da leitura e escrita, organização do pensamento [...]" (MST, 2008, p.4).

No período de 2001-2006,

\begin{abstract}
Ampliou-se, ainda mais, o número e a variedade de cursos oferecidos, em parceria com instituições públicas diversas e com o apoio de convênios governamentais. As Escolas Itinerantes foram reconhecidas em diversos estados.

Entretanto, o rápido crescimento implicou num certo distanciamento, identificado como uma crise do setor de educação [...] (GUHUR, 2010, p. 92).
\end{abstract}

O Movimento dos Trabalhadores Rurais Sem Terra, no Seminário do Coletivo Nacional de Educação, de 2008, ressalta que o setor educacional do movimento "[...] já não conhece a realidade das escolas, especialmente as dos assentamentos" (MST, 2008, p. 4), revelando que a crise da escola no movimento está relacionada "[...] à crise da escola 
em geral (ou desta forma histórica de escola), em função do acirramento das contradições do sistema capitalista e, em específico, às dificuldades enfrentadas na organização (e na produção) dos assentamentos" (GUHUR, 2010, p. 92).

Para Guhur (2010, p. 126), esta crise levou o Movimento dos Trabalhadores Rurais Sem Terra à retomada do debate sobre o papel da escola. Neste debate, a educação de nível médio e a articulação com a educação profissional passam a receber maior atenção em virtude de serem:

[...] os espaços educativos que mais expressam sua concepção de escola, nas suas tensões, contradições e reafirmação de princípios, em função da maior autonomia pedagógica alcançada nesses espaços (em comparação com as escolas da rede pública que existem nos assentamentos, por exemplo).

O objetivo fundamental dos cursos profissionalizantes é a formação de indivíduos sociais "[...] capazes de ler criticamente a sua realidade e nela intervir; para tanto, é preciso ir além da formação para/pelo trabalho, levando em conta outras dimensões na formação do trabalhador/trabalhadora: a luta social, a organização coletiva, a ciência, a cultura" (GUHUR, 2010, p. 127).

Desta forma, deve-se atentar para a formação específica em atendimento as demandas concretas na base do movimento e, principalmente, formar trabalhadores que produzam suas vidas por meio da luta, não se sujeitando a exploração do trabalho do mercado capitalista. "Até porque formação profissional não é garantia de trabalho e, portanto, não pode substituir a luta pelo direito ao trabalho (que, neste caso, passa também - mas não só - pelo direito à terra)" (GUHUR, 2010, p. 127).

O Movimento dos Trabalhadores Rurais Sem Terra concebe a formação técnica em Agroecologia como parte de um projeto político de transformação do indivíduo e da sociedade, restaurando o funcionamento harmonioso entre o homem e a natureza. Entretanto, este pleno desenvolvimento humano só se concretizará na superação da ordem social e das relações capitalistas, pois, como pontuam Novaes et al. (2015, p. 129-130), mesmo organizados, com prática de luta, conscientização política, os integrantes do Movimento dos Trabalhadores Rurais Sem Terra:

[...] sofrem também a influência e as pressões exercidas pelas grandes corporações transnacionais, que dominam a comercialização e a produção agroindustrial. Desse modo, nem todos os assentamentos do MST estão fundamentados na agroecologia. Por mecanismos diretos e indiretos, tais como a propaganda, que cria o fetiche da "revolução" verde, a influência de técnicos e agrônomos, ou por meio de instrumentos mais sutis, por exemplo, o atrelamento do crédito a aquisição do pacote da revolução verde, o capital cria as condições gerais para a produção estruturada nos moldes da "revolução" verde. Isso faz com que a forma habitual de produção agrícola fundamentada no uso de agrotóxicos, adubos sintéticos e tratores pesados, seja utilizada em parte dos assentamentos dos movimentos sociais [...].

Portanto, o maior desafio está na mudança para outras formas de produção, ou seja, na adoção da Agroecologia em um mercado capitalista. Assim, encontros são realizados para discutir os desafios na efetivação da Agroecologia nos Assentamentos deste movimento social.

Em São Paulo, em novembro de 2014, realizou-se o II Encontro Regional de Agroecologia do Pontal do Paranapanema, que reuniu assentados, estudantes, profissionais da assistência técnica e extensão rural e acampados da região, além de representantes de várias instituições parceiras que compõem a articulação da Rede Pontal Agroecológico. Neste evento, foram discutidos os desafios para a construção da 
agroecologia frente o atual modelo capitalista de produção, que segundo Delwek Matheus, da direção nacional do Movimento dos Trabalhadores Rurais Sem Terra, "[...] passa por uma ruptura radical com a forma da agricultura convencional, que vem envenenando os solos e destruindo a agrobiodiversidade" (MST, 2014).

O professor Luiz Carlos Pinheiro Machado, da Universidade Federal de Santa Catarina, na abertura deste evento, ressaltou que a agroecologia é uma proposta muito mais avançada do que o agronegócio, "[...] com a alta produtividade atingida na agricultura, mesmo que em pequenas áreas de terras, como o caso dos assentamentos" (MST, 2014).

Assim, após dois dias debatendo, principalmente, o papel da juventude e das mulheres na construção da agroecologia da Reforma Agrária Popular, os participantes deste encontro reafirmaram e defenderam, que:

A juventude rural tem papel absolutamente fundamental para o fortalecimento e reprodução dos Agricultores Familiares enquanto sujeitos de uma agricultura verdadeiramente camponesa. Nesse sentido, entendemos ser premente a organização de coletivos e fóruns para debater e propor ações integradas, visando criar condições efetivas para que os jovens permaneçam no campo de maneira digna e com perspectivas concretas de construção de uma vida melhor. Defendemos a ampliação e o aprimoramento de políticas públicas para o fortalecimento e consolidação da pesquisa, do ensino e de uma extensão rural comprometida com os princípios da agroecologia (MST, 2014).

Compreende-se, portanto, a importância atribuída, por este movimento social, a formação em Agroecologia, ao reafirmarem o fortalecimento da pesquisa e do ensino no mundo rural que atendam os princípios agroecológicos e, também, ao defenderem ampliação e o aprimoramento de políticas públicas dos programas de ação governamental que objetivam implementar políticas sociais na promoção do desenvolvimento democrático e sustentável do meio rural brasileiro.

Deve-se ressaltar que não há no Brasil um projeto nacional que instale políticas agrícolas para o fortalecimento das estruturas econômicas internas, visando a repartição das riquezas socialmente criadas. Desta forma, o Estado não assume o seu papel como gestor de um projeto de sociedade que supere as desigualdades sociais.

Esse padrão de gestão pública, em especial da política agrícola, implica a submissão às pressões das relações político-econômicas dominantes, sejam elas internas ou externas. Ao mesmo tempo, ela é indicativa da incapacidade dos governos de implementar políticas sociais vinculadas a uma perspectiva de superação estrutural da pobreza pela via da promoção do desenvolvimento democrático e sustentável. Pelo lado da sociedade civil organizada, sobretudo nos movimentos camponeses e da agricultura familiar de abrangência nacional, ainda é limitada a defesa dos referenciais da Agroecologia como eixo estruturador das pautas de negociação política com o Estado. Mesmo assim, continuam crescendo iniciativas de inovação sociopolítica e metodológica relevantes, destacando-se aí a emergência da Articulação Nacional de Agroecologia (ANA) e da Associação Brasileira de Agroecologia (ABAAgroecologia) [...] (CAPOROL; PETERSEN, 2012, p. 66-67).

A promoção do desenvolvimento do meio rural brasileiro através da agroecologia, só será concretizada se este desafio for assumido pela sociedade com o objetivo de superar “[...] no plano político a obstinada resistência da aliança entre os interesses das elites agrárias e agroindustriais brasileiras com o capital transnacional [...]" (CAPOROL; PETERSEN, 2012, p. 72). 
Assim, o Movimento dos Trabalhadores Rurais Sem Terra, utilizando-se dos debates e implementação de uma educação técnica em Agroecologia, caminha no desenvolvimento de projeto alternativo para o meio rural do Brasil, numa crítica à revolução verde.

Ao mesmo tempo em que criticam a revolução verde difundindo pesquisas, documentos críticos à produção destrutiva, críticas às patentes, agrotóxicos, transgênicos, etc., os cursos do MST colaboram para a construção da teoria e da prática, e contribui para a difusão dos princípios e fundamentos da agroecologia (NOVAES et al., 2015, p. 134).

Nas escolas de Agroecologia deste movimento, diferentemente dos cursos oferecidos pelas Escolas Técnicas Estaduais e Federais,

[...] é possível encontrar um currículo mais integrado entre ciências sociais e ciências duras, uma tentativa de apropriação do materialismo histórico e uma profícua relação entre teoria, com fundamentos científicos da agroecologia e crítica científica da revolução verde, e a prática, com experimentação agroecológica ((NOVAES et al., 2015, p. 134).

Entretanto, existem contradições e limites, desafios a serem superados, como a baixa apropriação teórica por parte dos alunos e, como:

[...] nem todos os professores são orgânicos ao MST, há problemas na integração das disciplinas, com relativa fragmentação do conhecimento, poucos recursos para a manutenção das escolas, poucos pesquisadores das Universidades e Institutos de Pesquisa desenvolvendo pesquisas agroecológicas, dentre outras (NOVAES et al., 2015, p. 134).

Deve-se evidenciar que, apesar das contradições e desafios presentes na efetivação das práticas educativas em Agroecologia, ela se caracteriza numa educação para além do capital no século XXI, ou seja, para além da escola capitalista que contribui na produção e reprodução dos interesses da classe dominante, interiorizando a cultura global da sociedade de consumo, pois somente "[...] a mais consciente ação coletiva pode destrinçálos desta grave situação paralisante" (MÉSZÁROS, 2008, p.45).

\section{Consideracões finais}

Neste trabalho, buscou-se a compreensão dos desafios da educação agroecológica do Movimento dos Trabalhadores Rurais Sem Terra frente às práticas capitalistas impostas ao Brasil, utilizando-se da pesquisa exploratória através da fundamentação teórica e exemplos da realidade estudada.

Verificou-se que os fatores que determinaram a estrutura agrária do Brasil Colônia, como a grande propriedade da terra, a monocultura e o trabalho escravo, se prolongaram no Brasil Império e, com exceção do trabalho escravo, estão presentes nas atividades exportadoras do País contemporâneo, do Agronegócio brasileiro, ou seja, na prática capitalista denominada "revolução verde": concentração de terras de poucos proprietários e das corporações internacionais que dominam o processo de produção dos insumos, sementes, adubos, agrotóxicos, máquinas agrícolas e as técnicas e tecnologias.

Como consequências da "revolução verde", os problemas socioambientais entraram em cena, como: desempregos, dívidas, doenças, expulsão dos pequenos proprietários, poluição, etc., em todas as regiões do Brasil, culminando em desigualdades, negação aos camponeses do direito à terra, à produção e à sobrevivência. 
Neste cenário de investida do capital e da ideologia neoliberal no campo brasileiro, o Movimento dos Trabalhadores Rurais Sem Terra atua na luta pela reforma agrária e implantação de políticas públicas no desenvolvimento socioeconômico dos assentamentos de trabalhadores rurais no Brasil. Dentre as ações contra a hegemonia do capitalismo no campo, este movimento social implementa, através de seus princípios pedagógicos, a Agroecologia, um campo de conhecimento de caráter multidisciplinar que se utiliza de princípios e conceitos ecológicos para o manejo sustentável, preocupando-se com o esgotamento do solo, a degradação dos recursos naturais e a produção sem a exploração da mão de obra.

Esta formação profissional em Agroecologia é orientada pelos princípios educacionais do Movimento dos Trabalhadores Rurais Sem Terra, como a autogestão, o trabalho, a auto-organização dos alunos e a gestão democrática. Entretanto, os desafios na realização destes princípios pedagógicos se evidenciam na medida em que esta pedagogia e as práticas educativas são desenvolvidas dentro da realidade social capitalista.

Ao implementar estas práticas educativas em Agroecologia, vivencia-se o convívio diário com as contradições do sistema, ou seja, a adoção de práticas ecológicas, sustentáveis e de desenvolvimento pleno do homem em um ambiente que sofre a influência, as pressões do Agronegócio na comercialização e a produção.

Deve-se pontuar, também, os problemas relacionados as práticas pedagógicas desenvolvidas nas escolas, como: problemas na integração das disciplinas e fragmentação do conhecimento em virtude da falta de organicidade dos professores, a dificuldade de apropriação teórica dos alunos, os mínimos recursos para a manutenção das escolas, a ausência de incentivos em pesquisa na Agroecologia, etc.

Contudo, apesar das contradições, problemas e desafios ressaltados, as práticas educativas em Agroecologia do Movimento dos Trabalhadores Rurais Sem Terra são essenciais para o rompimento da produção e reprodução da sociedade capitalista. Citando Mészáros (2008, p. 45), “[...] os remédios 'não podem ser formais; eles devem ser essenciais" "na quebra da reprodução da lógica do capital, pois contribui na criação de uma consciência social capaz de modificar o modo de ser do indivíduo social. Assim, a educação em Agroecologia do Movimento dos Trabalhadores Rurais Sem Terra torna-se imprescindível no planejamento e na aplicação de estratégias de transição para uma socialização para além do capital.

\section{$\underline{\text { Referências bibliográficas }}$}

BURAWOY, Michael. Marxismo sociológico. Quatro países, quatro décadas, quatro grandes transformações e uma tradição crítica. São Paulo: Alameda, 2014.

CALDART, Roseli Salete. O MST e a formação dos sem-terra: o movimento social como princípio educativo. In: Estudos Avançados. vol.15, no.43, São Paulo, set. /dez. 2001. Disponível em: http://dx.doi.org/10.1590/S0103-40142001000300016. Acesso em: 15 maio 2015.

CAPORAL, F.; COSTABEBER, J. Análise multidimensional da sustentabilidade - uma proposta metodológica a partir da Agroecologia. Revista Agroecologia e Desenvolvimento Rural Sustentável. Porto Alegre, v. 3, n. 3, p. 70-85, 2002.

CAPORAL, F.; PETERSEN, P. Agroecologia e políticas públicas na América latina: o caso do Brasil. In: Agroecologia, n. 6, 2012, p. 63-74. Disponível em: http://revistas.um.es/agroecologia/article/view/160681. Acesso em: 04 jul. 2015. 
COUTINHO, C. N. Gramsci: um estudo sobre seu pensamento político. Rio de Janeiro: Campus, 1989.

DAL RI, Neusa Maria; VIEITEZ, Candido Giraldez. A educação do movimento dos sem-terra. Revista Brasileira de Educação. Maio/Jun./Jul./ Ago. 2004, n. 26.

Educação democrática e trabalho associado no movimento dos trabalhadores rurais sem terra e nas fábricas de autogestão. São Paulo: Ícone: FAPESP, 2008.

GIL, Antônio Carlos. Como elaborar projetos de pesquisa. São Paulo: Atlas, 2002.

GONÇALVES, S. Campesinato, resistência e emancipação: o modelo agroecológico adotado pelo MST no Estado do Paraná. 2008. Tese (Doutorado em Geografia). Universidade Estadual Paulista, Presidente Prudente.

GUHUR, Dominique M. P. Contribuições do diálogo de saberes à educação profissional em agroecologia no MST: desafios da educação do campo na construção do projeto popular. 2010. 267f. Dissertação (Mestrado em Educação) - Universidade Estadual de Maringá, Maringá, PR.

GUHUR, Dominique M. P.; TONÁ, Nilciney. Agroecologia. In: CALDART, R.S; PEREIRA, I.B; ALENTEJANO, P; FRIGOTTO, G. (orgs.) Dicionário de educação do campo. Rio de Janeiro, São Paulo: Escola Politécnica de Saúde Joaquim Venâncio, Expressão Popular, 2012. p. 57-66.

LIMA, A. C. Práticas educativas em agroecologia no MST/PR: processos formativos na luta pela emancipação humana. 2011. 321 f. Dissertação (Mestrado em Educação) - Universidade Estadual de Maringá, Maringá, PR.

MARX, Karl; ENGELS, Friedrich. Manifesto do Partido Comunista. São Paulo: Expressão Popular, 2008.

MÉSZÁROS, István. A educação para além do capital. São Paulo: Boitempo, 2008.

MST - Movimento dos Trabalhadores Rurais Sem Terra, (1992). Como fazer a escola que queremos. In: Caderno de Educação. Porto Alegre, $\mathrm{n}^{\mathrm{o}} 1$. Disponível em: http://www.docvirt.com/docreader.net/DocReader.aspx ?bib=BibliotLT\&PagFis=7749\%22PagF is=7749 Acesso em: 12 nov. 2014.

MST - Movimento dos Trabalhadores Rurais Sem Terra, (1996). Princípios da educação do MST. In: Caderno de Educação. Porto Alegre, n ${ }^{\circ}$ 8. Disponível em:

http://www.docvirt.com/docreader.net/DocReader.aspx?bib=BibliotLT\&PagFis=7585\%22PagF is=7585 Acesso em: 12 nov. 2014.

MST. A agroecologia como modelo ideal de produção de alimentos. Disponível em: http://www.mst.org.br/2015/06/17/a-agroecologia-como-modelo-ideal-de-producao-dealimentos.html Acesso em: 3 jul. 2015.

MST. Educação. Disponível em: http://www.mst.org.br/educacao/ Acesso em: 17 maio 2016.

MST - Movimento dos Trabalhadores Rurais Sem Terra, (1999). Como fazer a escola que queremos. In: Caderno de Formação. Porto Alegre, $\mathrm{n}^{\circ}$ 18. Acesso em: http://www.docvirt.com/docreader.net/DocReader.aspx?bib=BibliotLT\&PagFis=7585\%22PagF is=7585 Acesso em: 20 mar. 2015. 
MST. Encontro de agroecologia debate projeto de agricultura para o Pontal (2014). Disponível em: http://www.mst.org.br/2014/12/02/encontro-de-agroecologia-debate-projeto-deagricultura-para-o-pontal.html Acesso em: 03 jul. 2015.

MST. O MST e a Escola: seminário do coletivo Nacional de Educação. Brasília: jun. 2008 (mimeo).

NOVAES, H. T. et al. A economia política da "Revolução Verde", a agroecologia e as Escolas de agroecologia do MST. In: NOVAES, H. T.; MAZIN, Angelo; SANTOS, Laís (Orgs). Questão Agrária, Cooperação e Agroecologia. Vol. I, Unesp Marília, 2015.

NOVAES, H. T. Reatando um fio interrompido: a relação universidade -movimentos social na América Latina. São Paulo: Expressão Popular-Fapesp, 2012.

PRADO Jr., Caio. A questão agrária no Brasil. São Paulo: Brasiliense, 1981.

2000.

Formação do Brasil contemporâneo: Colônia. São Paulo: Brasiliense/Publifolha,

SANTOS, Laís Ribeiro dos. A gestão democrática na educação profissional agroecológica do MST/Paraná: a experiência da escola Milton Santos. Rev. Tamoios. São Gonçalo (RJ), ano 10, n.2, p. 57-68, Jul./dez. 2014. 